\title{
Current distribution and status of the Eurasian otter Lutra lutra in South Korea
}

\author{
Yeong-Seok Jo, Oh-Sun Lee, Tae-Jin Park, Han-Na Kim and John T. Baccus
}

\begin{abstract}
The status of Asian populations of the Eurasian otter Lutra lutra is largely unknown. Since its designation as a Natural Monument (in 1983) and as Endangered (in 1997) in South Korea the authorities there have been trying to conserve and recover the species. We conducted a national otter survey by standard methods in 2017 and compared the current otter distribution to those recorded in a previous survey (2010). We found otter signs in $84.5 \%$ of 1,105 $10 \times 10 \mathrm{~km}$ grid cells, with the highest sprainting intensity in the south-west in the Yeongsan River Basin and on the south coast, where we recorded 7.05 and 6.26 spraints/site, respectively. Despite relatively low spraint densities, the otter has expanded its range since 2010 by colonizing urban areas. This trend suggests that South Korea could be a source area for the recovery of the Eurasian otter in East Asia.
\end{abstract}

Keywords East Asia, Lutra lutra, otter, population trend, species recovery, spraint, standard method

$\mathrm{n}$ the 20 th century, fur harvest and water pollution caused 1 a global decline in Eurasian otter Lutra lutra populations (Mason \& Macdonald, 1986). National and international conservation efforts have reversed this trend, and otters have returned to former habitats in several European countries (Romanowski et al., 2013). In 2004 the otter's IUCN Red List status was changed from Vulnerable to Near Threatened (Roos et al., 2015). In Asia, however, the Eurasian otter is still threatened in most countries and has been extirpated in Japan (Jo et al., 2017).

Unlike in Europe, where some countries have conducted periodic national and regional surveys, the monitoring of otter populations by the standard method (Reuther et al., 2000) has rarely been implemented in Asian countries (Jo et al., 2017). The first otter surveys in South Korea were conducted during 2002-2004, based on a national cartographic grid $(13.75 \times 11 \mathrm{~km}$; Jo et al., 2006), and during 2009-2010

\footnotetext{
YeONG-Seок Jo (Corresponding author) National Institute of Biological Resources, Hwangyeong-ro 42, Seo-gu, Incheon 22689, South Korea E-mail biostan@hotmail.com (D) https://orcid.org/0000-0002-0711-3871

Он-SUn LeE Jeonnam National University, Gwangjoo, South Korea

TAE-JIN PARK Gyeongsang National University, Jinjoo, South Korea

HAN-NA Kim National Institute of Biological Resources, South Korea

John T. BAccus Texas Tech University, Lubbock, Texas, USA

Received 5 May 2018. Revision requested 26 July 2018.

Accepted 10 August 2018. First published online 18 December 2018.
}

using a $10 \times 10 \mathrm{~km}$ Universal Transverse Mercator grid (Jo et al., 2017).

Because otters are elusive and Korea had few wildlife scientists after the Korean War, it was believed that this species had been almost extirpated (Won, 1967) and, consequently, the South Korean government designated the Eurasian otter as a Natural Monument in 1983 and as Endangered in 1997 (Jo et al., 2017). Subsequent surveys (in 2002-2004 and 2009-2010) indicated a nationwide otter distribution, and in 2011 the endangered species committee of Korea suggested that Lutra lutra be removed from the endangered species list (Jo, 2015). However, because of uncertainty about any trend, the Eurasian otter remained on the list. In the 2017 national otter survey our goals were to validate the nationwide otter distribution and to assess any trend by comparing the results with those of the previous surveys.

We conducted a comprehensive nationwide survey for otter sprainting sites, i.e. locations where otter dung is found (Fig. 1). We surveyed 1,105 grid cells $(10 \times 10 \mathrm{~km}$; Fig. 2), inspecting at least one plausible otter habitat, such as river stretches, lake shores, reservoirs and freshwater sources in coastal habitats (Jo et al., 2017), per grid. We conducted field surveys during January-March 2017 and added road-kill data recorded in 2017. We assessed otter presence or absence by walking a $1 \mathrm{~km}$ stretch along river banks and shorelines (Mason \& Macdonald, 1987). To avoid bias, we hired the same field surveyors as in 2010 and we trained newly recruited surveyors with the previous participants. We recorded the location of sprainting sites with a GPS. If we found no otter signs we recorded the site as negative for otters. To compare relative otter abundance among river systems or river basins, we recorded the number of spraints (Mason \& Macdonald, 1987). For the classification of river systems we followed the definition of the Korean River Act, in which a river system is defined as a river with drainage area $>200 \mathrm{~km}^{2}$.

We surveyed 1,664 sites and found otter signs at 1,267 (76\%). A total of 934 grid cells (84.5\%) were positive for otters (Fig. 2). Despite a dead otter (the victim of road-kill) having been recorded on Jeju Island in 2018, we did not find any additional sign of otter presence on the island.

The mean number of spraints per sprainting site was 4.71. The Yeongsan River Basin had the highest mean number of spraints per site (7.05), followed by the south coast (6.26) and Geum River Basin (5.09). The lowest mean number of spraints occurred on the west coast (2.21). The east coast (3.48), Han River Basin (3.60) and Nacdong River Basin 


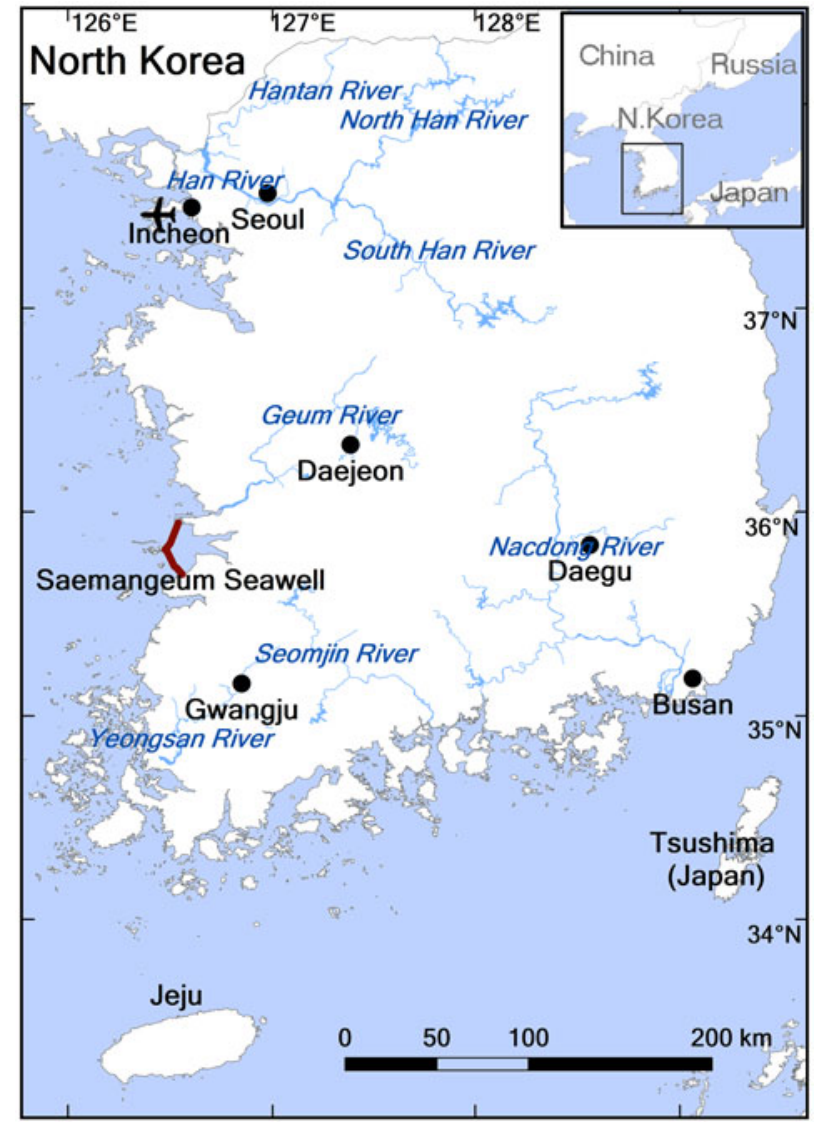

FIG. 1 Major rivers and cities of South Korea, where a nationwide survey of Eurasian otters Lutra lutra was conducted in 2017.

(4.03) had a mean number of spraints lower than the national mean (Fig. 3). For river systems positive for otters the mean number of spraints was 1-15 (Fig. 3).

A comparison of the 2010 and 2017 surveys indicates that the range of the otter has increased. In 2017 we recorded 254 more grid cells positive for otters (Fig. 4), although no otter sign was found in 15 grid cells that were positive for otters in 2010. The per cent of otter-positive grid cells increased from 63.3 to $84.5 \%$. We identified the range expansion from high marking intensity in reclamation areas (Saemangeum and Sihwa Seawalls) and urban water systems (Seoul, Busan, Daegu and Daejeon).

The project to construct the $33.9 \mathrm{~km}$ Saemangeum Seawall ran from 1991 to 2010. In the 2010 survey signs of otters were not found in most water systems around the project area (Jo et al., 2017), but in 2017 otter signs were widespread, suggesting that the species does not tolerate construction activities (Weinberger et al., 2016) but can recover rapidly when disturbance factors are removed. In Busan, the second largest city in Korea, there was an expansion of otter presence in and around the city. The Busan New Port project and Busan-Goeje fixed-link project, two large-scale national construction efforts, were completed

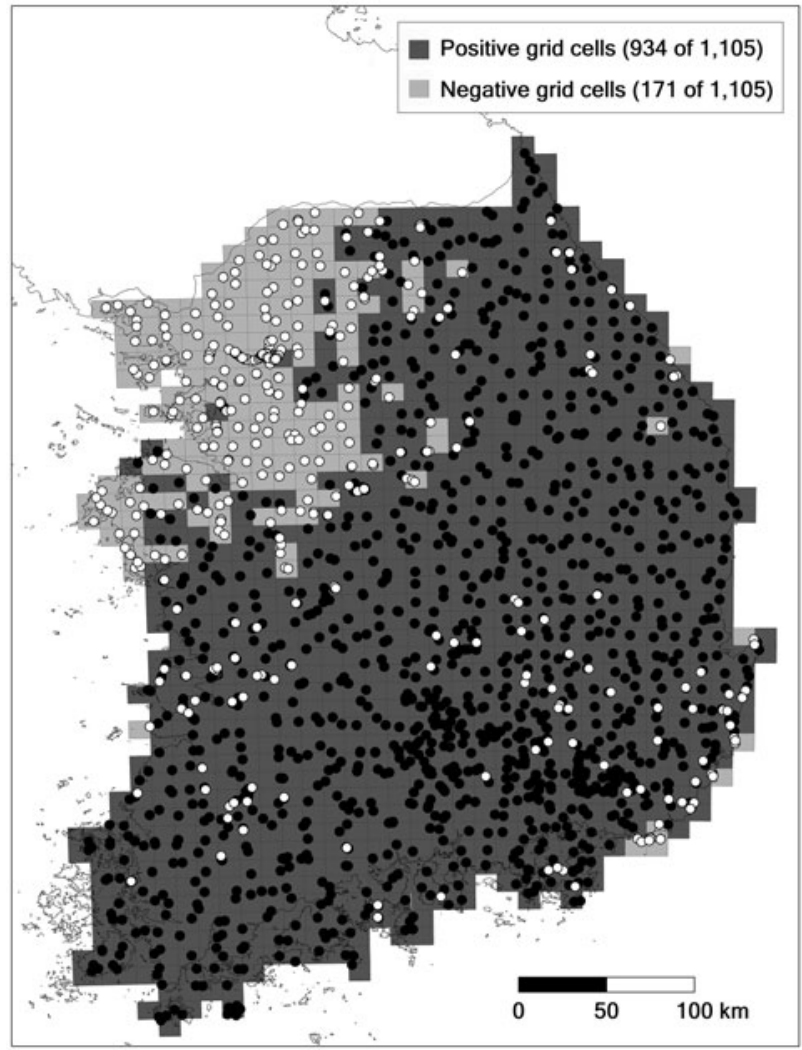

FIG. 2 Eurasian otter detection (black dots) and non-detection sites (white dots) in South Korea, based on a $10 \times 10 \mathrm{~km}$ Universal Transverse Mercator grid.

in 2010, after the 2010 otter survey. We recorded a return of otters to the area 7 years after massive landscape disturbances by these projects. Construction activities seem to have had a greater negative effect on the presence of otters than the higher volume of traffic after construction. As with the Saemangeum area, this region may be another example of the relationship between otter occurrence and the impacts of anthropogenic disturbance.

After the last otter there died in 1983, the Seoul metropolitan area on the west coast, with a human population of c. 2 million, had been regarded as unsuitable habitat for otters (Jo et al., 2006, 2017). The 2010 survey failed to find otter signs there (Jo et al., 2017). In 2017 we repeatedly recorded spraints under the city's Gwangjin Bridge but we did not find any additional otter signs in the area. We were unable to confirm previous records at Incheon International Airport and on the River Hantan, near Seoul. Further monitoring is needed to ascertain whether otters are transient or resident in Seoul, and how we may enhance otter expansion in the surroundings of this metropolitan area.

In addition to expansion on the Korean Peninsula, otters have recently been reported on nearby islands. It has been proposed that the individual found as road-kill on Jeju Island may have travelled to the island aboard a fish cargo boat rather than swimming there from the Korean 


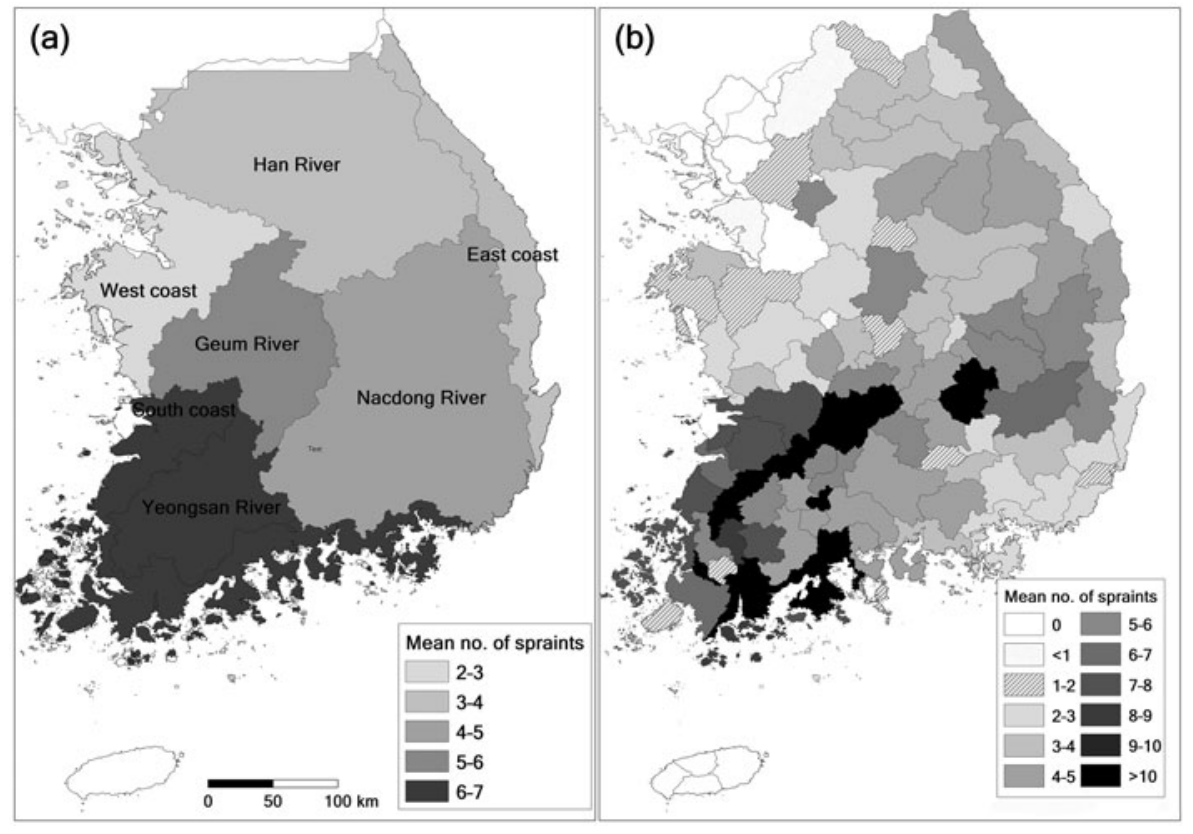

FIG. 3 Mean number of spraints recorded per sprainting site for (a) river basins and (b) major river systems in South Korea.

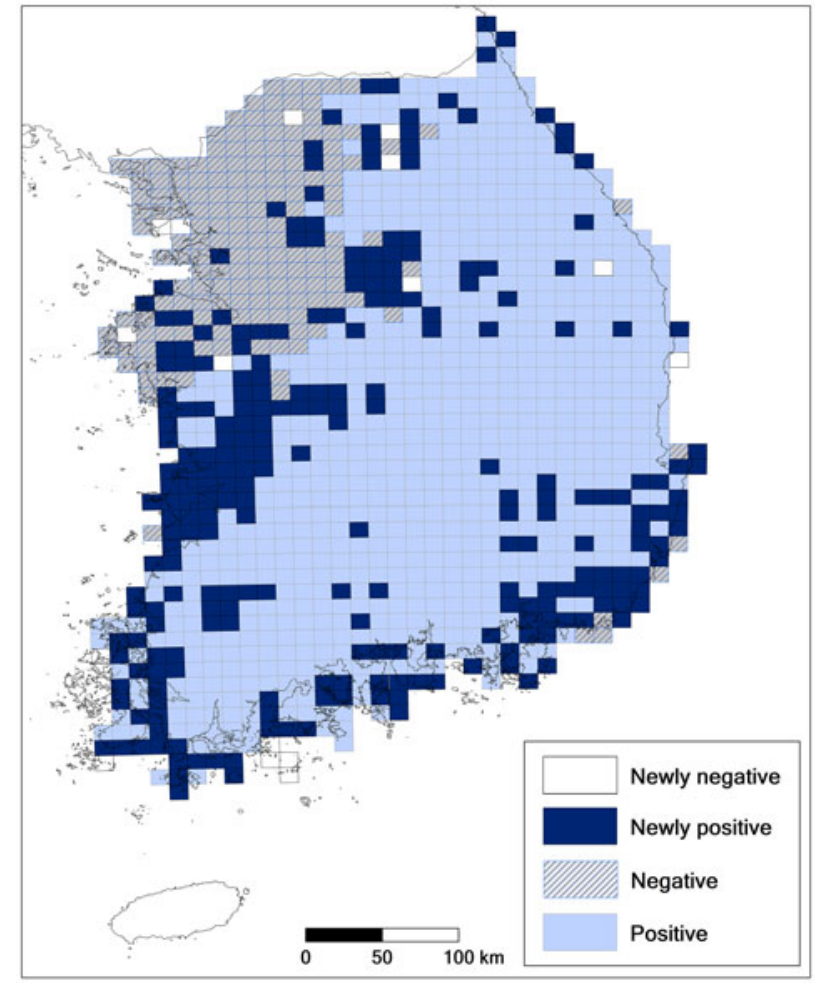

FIG. 4 Changes in otter distribution in South Korea between the 2010 and 2017 surveys. In 2017 otter signs were not detected in 15 grid cells (newly negative) that were positive for otters in 2010, whereas otter occurrence was confirmed in 254 cells (newly positive) that were negative for otters in 2010. There was no change in otter presence in other cells between the two surveys (negative, positive).

Peninsula (Dr S.Y. Han, Otter Conservation Center, Hwacheon, pers. comm.). In 2017 otters were also recorded on Tsushima Island (Japan; N. Naganishi \& M. Izawa, unpubl. data), indicating that otter recovery in Korea may enhance the recolonization of neighbouring islands.

Although the use of marking intensity as an index of otter abundance has been disputed (Kruuk \& Conroy, 1987), spraint counts have been used for broadly comparing otter numbers amongst populations (Mason \& Macdonald, 1987; Lanszki et al., 2008). In our survey, the river basins in the southwestern Korean Peninsula had higher numbers of spraints per site than other places (Fig. 3), whereas the lowest numbers were recorded in the metropolitan areas of Seoul and Busan.

Although the status of otters in Europe has been relatively well monitored and European populations have increased following conservation efforts, Asian populations remain relatively unknown and most have declined ( $\mathrm{Li} \&$ Chan, 2017). Public interest and conservation efforts for the species have facilitated the recovery of otters in South Korea (Hong et al., 2017), and recovering otter populations in the country may be an important source for otter conservation elsewhere in East Asia.

Acknowledgements Sungwon Hong, Hyeong-Hoo Kim, Ji-Hyeon $\mathrm{Kim}$ and Ki-Cheol $\mathrm{Oh}$ assisted with field surveys. The National Institute of Biological Resources supported this national otter survey as part of the Wildlife Survey (NIBR 201824101). We thank two anonymous reviewers for valuable suggestions and comments that helped improve this article.

Author contributions Study design and writing: YSJ, JTB; fieldwork: YSJ, OSL, TJP, HNK.

\section{Conflicts of interest None.}

Ethical standards Our survey had the necessary approvals and permits from the Ministry of Environment of Korea. No animals were collected or killed during this study. 


\section{References}

Hong, S., Do, Y., Kim, J.Y., Cowan, P. \& Joo, G.J. (2017) Conservation activities for the Eurasian otter (Lutra lutra) in South Korea traced from newspapers during 1962-2010. Biological Conservation, 210, 157-162.

Jo, Y.S. (2015) Mammals of Korea: Conservation and Management. $\mathrm{PhD}$ thesis. Texas Tech University, Lubbock, USA.

Jo, Y.S., Won, C.M. \& KIM, J.P. (2006) Distribution of Eurasian otter Lutra lutra in Korea. Korean Journal of Environmental Biology, 24 89-94.

Jo, Y.S., Won, C.M., Fritts, S.R., Wallace, M.C. \& Baccus, J.T. (2017) Distribution and habitat models of the Eurasian otter, Lutra lutra, in South Korea. Journal of Mammalogy, 98, 1105-1117.

KRUUK, H. \& Conroy, J.W.H. (1987) Surveying otter Lutra lutra populations: a discussion of problems with spraints. Biological Conservation, 41, 179-183.

Lanszki, J., Hidas, A., Szentes, K., Révay, T., Lehoczky, I. \& WEISS, S. (2008) Relative spraint density and genetic structure of otter (Lutra lutra) along the Drava River in Hungary. Mammalian Biology, 73, 40-47.

Li, F. \& Chan, B.P.L. (2017) Past and present: the status and distribution of otters (Carnivora: Lutrinae) in China. Oryx, published online 21 June 2017
Mason, C.F. \& Macdonald, S.M. (1986) Otters: Ecology and Conservation. Cambridge University Press, Cambridge, UK.

Mason, C.F. \& Macdonald, S.M. (1987) The use of spraints for surveying otter Lutra lutra populations: an evaluation. Biological Conservation, 41, 167-177.

Reuther, C., Dolch, D., Green, R., Jahrl, J., Jefferies, D., Krekemeyer, A. et al. (200o) Surveying and Monitoring Distribution and Population Trends of the Eurasian Otter (Lutra lutra). Habitat, 12. GN-Gruppe Naturschutz GmbH, Hankensbüttel, Germany.

Romanowski, J., BrzeZiński, M. \& ZMihorski, M. (2013) Habitat correlates of the Eurasian otter Lutra lutra recolonizing central Poland. Acta Theriologica, 58, 149-155.

Roos, A., Loy, A., De Silva, P., Hajkova, P. \& Zemanová, B. (2015) Lutra lutra. In The IUCN Red List of Threatened Species 2015: e. T12419A21935287. Http://dx.doi.org/10.2305/IUCN.UK.2015-2.RLTS. T12419A21935287.en [accessed 14 June 2016].

Weinberger, I.C., Muff, S., de Jongh, A., Kranz, A. \& Bontadina, F. (2016) Flexible habitat selection paves the way for a recovery of otter populations in the European Alps. Biological Conservation, 199, 88-95.

Won, P.H. (1967) Illustrated Encyclopedia of Fauna and Flora of Korea. Volume 7: Mammals. Ministry of Education, Seoul, South Korea. 